\title{
Article
}

\section{Glucose-6-Phosphate Dehydrogenase (G6PD) status in Female Type 2 Diabetes Mellitus and Its Relationship with $\mathrm{HbA}_{1} \mathrm{C}$}

\author{
Nadira Akter ${ }^{1}$, Noorzahan Begum ${ }^{2}$, Sultana Ferdousi ${ }^{3}$
}

\begin{abstract}
Background: Glucose-6-phosphate dehydrogenase (G6PD) deficiency may be one of the risk factor for type 2 diabetes mellitus. Objective: To observe erythrocyte G6PD status in type 2 female diabetic patients and also to find out its relationship with glycosylated hemoglobin. Methods: This cross sectional study was carried out in the Department of Physiology, Bangabandhu Sheikh Mujib Medical University, Shahbag, Dhaka from January to December 2009. For this, 60 female patients with type 2 diabetes mellitus, age ranged from 40 to 60 years were included in the study group (group B). On the basis of glycosylated hemoglobin level ( $\mathrm{HbA} 1 \mathrm{C}$ ) they were further subdivided into group $\mathrm{B}_{1}$, consisting of 30 controlled diabetics $\left(\mathrm{HbA}_{1} \mathrm{C} 4.8-6 \%\right)$ and group $\mathrm{B}_{2}$, consisting of 30 uncontrolled diabetic $\left(\mathrm{HbA}_{1} \mathrm{C}>6 \%\right)$ patients. They were selected from Out Patient Department of Bangladesh Institute of Health Science Hospital. For comparison, age \& sex matched 30 apparently healthy non diabetic females (group A) were also studied. Erythrocyte G6PD level was measured by Spectrophotometer, $\mathrm{HbA}_{1} \mathrm{C}$ level by Flex reagent cartridge and serum bilirubin, $\mathrm{Hb} \%$, total count of $\mathrm{RBC}$ and reticulocyte\% were measured by standard laboratory techniques. For statistical analysis ANOVA, independent sample t test, $\chi^{2}$ test and Pearson's correlation coefficient test were performed as applicable. Results: In this study, erythrocyte G6PD level was significantly lower in both the diabetic groups ( $\mathrm{p}<0.001)$ than those of control group but their difference when compared between $B_{1}$ and $B_{2}$ was not statistically significant. In controlled diabetics $20 \%$ and in uncontrolled diabetics $6.7 \%$ patients were found G6PD deficients. No G6PD deficient subjects were found in control group. $\mathrm{HbA}_{1} \mathrm{C}$ showed negative correlation with Erythrocyte G6PD which was only significant for uncontrolled diabetes $(\mathrm{p}<0.05)$ Conclusion: This study concludes that G6PD deficiency may be one of the risk factor for type 2 diabetes mellitus irrespective of blood glucose control status..
\end{abstract}

Key word: Glucose-6-PD, Diabetes, Female.

J Bangladesh Soc Physiol. 2010 December; 5(2): 60-65 For author affiliations, see end of text.

http://www.banglajol.info/index.php/JBSP

\section{Introduction}

D

iabetes mellitus is a multifactorial disease resulting from interaction of both genetic and environmental factors $^{1}$. Both the insulin resistance and decreased insulin secretion are the major features of the pathophysiology of type 2 diabetes and typically affects individuals older than 40 years ${ }^{2}$.
It has been stated that oxidative stress and impaired release of nitric oxide may be the contributory factors in the pathogenesis of diabetes ${ }^{3}$. Recently, researchers found that G6PD deficient individuals may suffer from an episode of raised $\mathrm{H}_{2} \mathrm{O}_{2}$, which acts as an oxidant and thereby may lead to development of type 2 
diabetes mellitus ${ }^{4}$. According to Beutler et al., G6-PD deficiency is one of the common enzymopathy in human being affecting about 400 million people worldwide $\mathrm{e}^{5-7}$. It is suggested that there may be a positive association of G6PD deficiency with diabetes mellitus. ${ }^{8} 9$.The link between diabetes mellitus and G6PD deficiency has been currently focused in many studies ${ }^{5-9}$ It has been reported that glucose tolerance is altered in subjects with G6PD deficiency characterized by accumulation of glucose in alternative pathway, which increases the advanced glycosylated end product ${ }^{3,10}$. Prolonged hyperglycemia may increase the work load on G6PD enzyme to convert glucose-6phosphate to 6-phosphogluconate followed by its excessive metabolic disintegration and thereby results in reduced G6PD activity or G6PD deficiency $^{11}$. Recently, it has been reported that oxidative stress leads to development of late complications of diabetes and also participates in beta cell dysfunction or insulin resistance ${ }^{12}$. In a state of oxidative stress, most of the glutathione is consumed. Enzymes and other proteins are subsequently damaged by oxidants ${ }^{9}$. Therefore lower blood G6PD activity and lower intake of antioxidants are found to be risk factor for occurrence of the disease ${ }^{13}$. Various investigators reported that G6PD deficient individuals have lower antioxidant stores which makes them vulnerable to oxidative stress. So, lower intake of antioxidant specially in G6PD deficient state, carries higher risk for diabetes mellitus ${ }^{14}$. In our country, diabetes related complications are the usual findings in diabetic patients. Associated deficiency of enzyme G6PD may enhance these complications. Although G6PD deficiency is not uncommon in our country but there is scarcity of data on this regards especially on diabetes. A good number of studies in other countries ${ }^{5-7,11,13}$ have demonstrated high prevalence of G6PD deficiency in diabetic patients but no such published data is available in Bangladesh.
Therefore, this study was undertaken to observe the erythrocyte G6PD status in female patients with type 2 diabetes mellitus in order to explore the role of this enzyme deficiency as one of the risk factor for diabetes mellitus \& also to observe its relationship with HbA1c level. Moreover, the finding of this study may also be helpful to the clinicians for better management of the complications of diabetes mellitus.

\section{Methods}

The present cross sectional study was carried out in the Department of Physiology, BSMMU, Dhaka between January 2009 to December 2009 and the protocol was approved by the ethical committee of the Department of Physiology. Total number of 90 female subjects of 40 to 60 years of age were included in this study. 60 patients with type 2 diabetes were taken as the study groups (group B). Thirty (30) age and sex matched apparently healthy non-diabetic subjects were considered as control (group A). On the basis of blood $\mathrm{HbA}_{1} \mathrm{C}$ level, study group was further subdivided into two subgroups. 30 patients with $\mathrm{HbA}_{1} \mathrm{C}$ (4.8-6\%) were designated as controlled diabetics and constituted group $\mathrm{B}_{1}$ and 30 patients with $\mathrm{HbA}_{1} \mathrm{C}(>6 \%)$ were termed as uncontrolled diabetes and were included in group $\mathrm{B}_{2}$. Patients with presence of hypertension (diastolic B.P> $90 \mathrm{mmHg}$ and systolic B.P>140 $\mathrm{mmHg}$ ), cataract and history of any heart diseases were excluded from the study. All the study subjects (group B) were selected from Out Patient Department of Bangladesh Institute Of Health Sciences Hospital (BISH), Dhaka and control (group A) were selected by personal contact. After selection of the subjects, the purpose of the study was explained to each subject. When they agreed for participation, then an informed written consent was taken. Detailed family and medical history were taken. Thorough Physical examinations were done and all informations were recorded in a prefixed questionnaire. Then $5 \mathrm{ml}$ of venous blood was collected from ante-cubital vein from each subject for estimation of hematological and biochemical tests. 
Blood G6PD enzyme activity was determined by Spectrophotometric method and Glycosylated Hemoglobin was estimated by Flex reagent cartridge method. $\mathrm{HbA}_{1} \mathrm{C}$ level was estimated in the laboratory of the Department of Biochemistry and other hematological tests were done in the hematological laboratory of the Department of Physiology of BSMMU, Dhaka. Data were expressed as mean \pm SD. Data analysis was done with SPSS version 12 . For statistical significance, one way ANOVA and Pearson correlation coefficient test were used.

\section{Results}

In this study, all the groups were matched for age but the mean BMI were significantly higher in group $B_{1}$ and $B_{2}(p<0.01)$ in comparison to that of group A. But this value was almost similar in group $B_{1}$ and $B_{2}$. (Table $I$ ).

Table I : Age and BMI in different groups of subjects $(\mathrm{n}=90)$.

\begin{tabular}{lccc}
\hline Groups & $\mathrm{n}$ & Age $(\mathrm{yrs})$ & $\mathrm{BMI}\left(\mathrm{kg} / \mathrm{m}^{2}\right)$ \\
\hline $\mathrm{A}$ & 30 & $45.57 \pm 1.72$ & $24.30 \pm 1.21$ \\
$\mathrm{~B}_{1}$ & 30 & $46.17 \pm 2.40$ & $25.50 \pm 1.15$ \\
$\mathrm{~B}_{2}$ & 30 & $46.23 \pm 1.43$ & $25.59 \pm 2.02$ \\
\hline
\end{tabular}

Statistical Analysis:

\begin{tabular}{lll}
\hline & \multicolumn{2}{c}{ P value } \\
\hline $\mathrm{A}$ vs $\mathrm{B}_{1}$ vs $\mathrm{B}_{2}$ & $0.270^{\mathrm{ns}}$ & $0.002^{* *}$ \\
$\mathrm{~A}$ vs $\mathrm{B}_{1}$ & $0.222^{\mathrm{ns}}$ & $0.001^{* * *}$ \\
$\mathrm{~A}$ vs $\mathrm{B}_{2}$ & $0.108^{\mathrm{ns}}$ & $0.004^{* *}$ \\
$\mathrm{~B}_{1}$ vs $\mathrm{B}_{2}$ & $0.884^{\mathrm{ns}}$ & $0.829^{\mathrm{ns}}$ \\
\hline
\end{tabular}

Data expressed as mean \pm SD

Group A = Apparently healthy non diabetic subjects (Control group).

Group B = Type 2 diabetic female patients (Study group).

Group $\mathrm{B}_{1}=$ Controlled

Group $\mathrm{B}_{2}=$ Uncontrolled

$$
* *=\mathrm{p}<0.01 \quad \mathrm{~ns}=\text { Non significant }
$$

$* * *=\mathrm{p}<0.001 \mathrm{n}=$ Number of subjects.
The mean erythrocyte G6PD levels were significantly $(p<0.001)$ lower in both the study groups $\mathrm{B}_{1}$ and $\mathrm{B}_{2}$ in comparison to that of control group $A$. On the other hand, though this value was lower in group $\mathrm{B}_{2}$ in comparison to that of group $B_{1}$ but the difference was statistically not significant. (Figure 1)

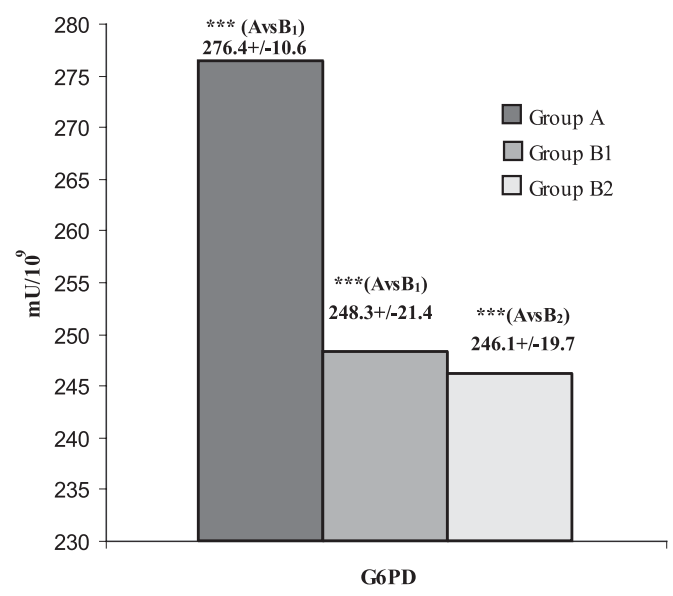

Data are expressed as Mean \pm SD.

Group A = Apparently healthy non diabetic subjects (Control group).

Group B = Type 2 diabetic female patients (Study group). Group $\mathrm{B}_{1}=$ Controlled

Group $\mathrm{B}_{2}=$ Uncontrolled $* *=\mathrm{p}<0.01 * * *=\mathrm{p} £ 0.001$

Figure 1: Erythrocyte G6PD level in different groups of subjects $(n=90)$.

In this study, 6 (20\%) of the controlled diabetics and 2 (6\%) of uncontrolled diabetic subjects were G6PD deficient and they had G6PD level below $<245 \mathrm{mU} / 10^{9} \mathrm{RBC}$ and $<200 \mathrm{mU} / 10^{9} \mathrm{RBC}$ respectively. Though the percentage of G6PD deficiency was higher in $B_{1}$ than that of $B_{2}$ but the difference was statistically non significant. (Figure 2 \& Table II )

The relationship of G6PD with $\mathrm{HbA}_{1} \mathrm{c}$ showed negative correlatation with $\mathrm{HbA}_{1} \mathrm{C}$ in the diabetic groups which was statistically significant for group $\mathrm{B}_{2}(\mathrm{r}=-0.425$; $\mathrm{p}<0.05)$ but not for group $B_{1}(r=-0.331 p<0.05)$. (Figure 3$)$ 


\section{Article}

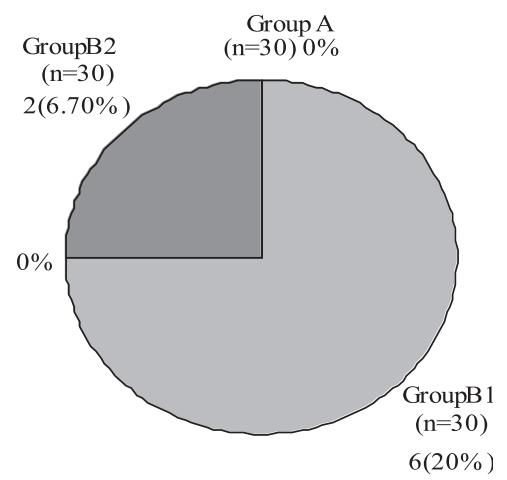

Figure 2: Distribution of the subjects by erythrocyte G6PD deficiency in different groups ( $\mathrm{n}=90$ ).

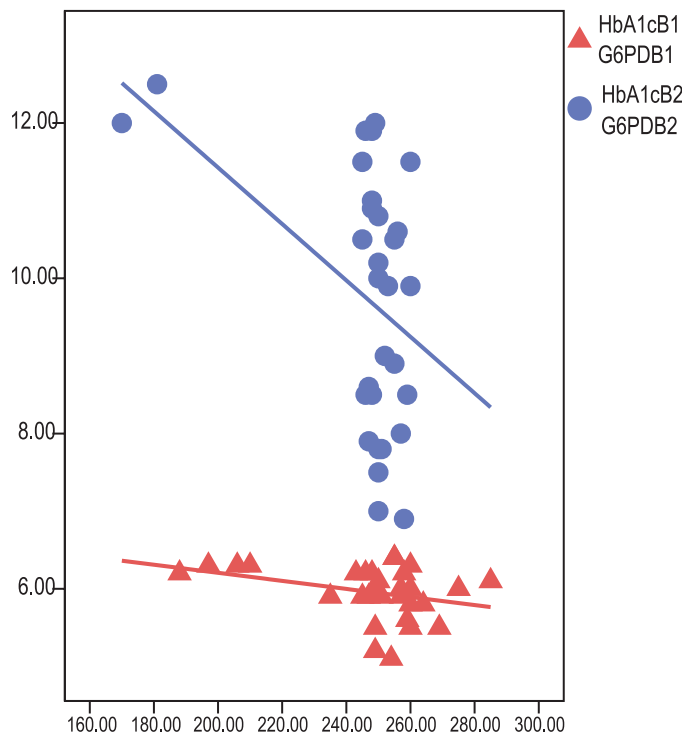

Figure 3: Correlation of $\mathrm{HbA}_{1} \mathrm{C}$ with erythrocyte G6PD level in diabetic groups $(\mathrm{n}=60)$

Table-II: Distribution of the subjects by erythrocyte G6PD level in diabetic groups ( $\mathrm{n}=60$ ).

\begin{tabular}{lcc}
\hline $\begin{array}{l}\text { G6PD level } \\
\left(\mathrm{mU} / 10^{9} \mathrm{RBC}\right)\end{array}$ & $\begin{array}{c}\text { Diabetic } \\
\text { Controlled } \\
\text { no (\%) }\end{array}$ & $\begin{array}{c}\text { subjects } \\
\text { Uncontrolled } \\
\text { no (\%) }\end{array}$ \\
\hline $245-299$ & $24(80 \%)$ & $28(93 \%)$ \\
$<245$ & $06(20 \%)$ & $0(0 \%)$ \\
$<200$ & $0(0 \%)$ & $02(6.6 \%)$ \\
\hline
\end{tabular}

Controlled $=\mathrm{HbA}_{1} \mathrm{C} 4.8-6 \%$

Uncontrolled $=\mathrm{HbA}_{1} \mathrm{C}>6 \%$
G6PD in Type 2 Diabetes

\section{Discussion}

In the present study, mean erythrocyte G6PD level in the healthy subjects was within normal range and almost similar to those observed by the investigators from different countries. ${ }^{13,15}$

Significantly lower mean erythrocyte G6PD level in both the groups of diabetics compared to non diabetics in this study is comparable to the findings reported by other researchers. ${ }^{13,15,16}$.

In the present study, no G6PD deficiency was found in non diabetic healthy control which is consistent to some other investigators ${ }^{13}$ but two studies found $10 \%$ and $2 \%$ enzyme deficiency in non diabetics ${ }^{12,15}$.

On the other hand, in 26\% deficiency of enzyme of diabetic patients is similar to those reported by some investigators ${ }^{12,13,15}$ where they found 14\%, 7\% and 3\% G6PD enzyme deficient diabetic females in Iraq, Saudi-Arabia and Taiwan respectively. In this study, the percentage of G6PD deficiency was higher in controlled than that of uncontrolled diabetes. Similar observation was also made by Niazi ${ }^{15}$. Furthermore, the results of the study showed a positive association between G6PD deficiency and diabetes which is also similar to the findings observed by some other investigators ${ }^{12,13,15}$.

Again, in the present study $\mathrm{HbA}_{1} \mathrm{C}$ showed significant negative correlation with Erythrocyte G6PD level in uncontrolled diabetes.

It has been suggested that various factors attributed to the association of the G6PD deficiency with diabetes mellitus. It has been suggested that G6PD deficient individuals are highly susceptible to oxidative stress, which is one of the risk factor for diabetes, and thereby lower activity of this enzyme may be a causative factor for diabetes. It may be related to DM related gene transmitted from the ancestor of G6PD deficient subjects. Genetic deficiency of G6PD is probably the result of rather than a predisposing cause of diabetes mellitus ${ }^{12}$. 
In this study, higher incidence of G6PD deficiency observed in controlled diabetes in comparison to that of uncontrolled diabetes may be link to the fact that this deficiency is possibly masked in uncontrolled diabetes ${ }^{15}$.

Oxidative stress causes alteration of membrane fluidity, decrease availability of NO and increased intracellular calcium content thereby may lead impairment of insulin action ${ }^{12}$.

In addition, increase in advanced glucosylating end products may be related to excess buildup of glucose in the polyol pathway due to deficiency of G6PD ${ }^{16}$.

In the present study, a few percentage of diabetic female showed deficiency of G6PD which is in favor of the suggestion that this enzyme deficiency may be a risk factor for the occurrence of the disease. Again, higher percentage of G6PD deficiency in controlled diabetes in comparison to that of uncontrolled diabetes of the present series indicates the higher incidence of the enzyme deficiency in this group of diabetic patients. On the other hand, markedly lower value of this enzyme in deficient patients of uncontrolled diabetes is in favor of the suggestion that enzyme level is markedly lower in uncontrolled diabetes.

\section{Conclusion}

This study reveals that, G6PD deficiency may be a risk factor for type 2 diabetes mellitus which may be linked to increased oxidative stress in deficient subjects. Therefore, routine screening of G6PD enzyme in type 2 diabetes patients is necessary to provide appropriate medical care such as supplementation of antioxidant and thereby may be helpful to minimize diabetes related other complications.

\section{Acknowledgement}

The authors of this article acknowledge Bangladesh Institute of Health Sciences Hospital (BIHS) for allowing sample collection.

\section{Author Affiliations}

1. * Nadira Akter. Senior Lecturer, Department of Physiology, Gonoshastha Samaj Vittik Medical College, Savar, Dhaka, Bangladesh. Email: nadira.akter@gmail.com

2. Noorzahan Begum, Professor, Department of Physiology, BSMMU, Shahbag, Dhaka, Bangladesh. Email:noorzahan52@gmail.com

3. Sultana Ferdousi, Assistant Professor, Department of Physiology BSMMU, Shahbag, Dhaka, Bangladesh.Email:sferdousiratna@gmail.com ; sferdousiratna@yahoo.com

\section{References}

1. Deo SS, Gore SD, Deobagkar DN, Deobagkar DD. Study of inheritance of diabetes mellitus in western Indian population by pedigree analysis. JAPI. 2006; 54: $441-43$.

2. Scott VR, Peters AL. Diabetes mellitus type 2 - A review.Emergency Medicine. [Internet] 2010, Jan 29. [Cited 2010 March 6]: Available from:http:/ www.shvoong.com/exact-cience/766143.

3. Gaskin R. Diet, Diabetes, Hypertension and Blacks. Ethnicity \& Disease. 1999; 9: 272-77.

4. Altomare E, Vendemiale G, Chicco D, Procacci V, Cirelli F.Increased lipid peroxidation in type 2 poorly controlled diabetic patients. Diabetes \& Metabolism. 1992; 18(4), 264-71.

5. Beutler E. Glcose-6-phosphate dehydrogenase deficiency. Blood. 1994; 84(11):3613-36.

6. Luzzatto L. Glucose 6- phosphate dehydrogenase deficiency: from genotype to phenotype. Hematology.2006; 2:63-8.

7. Carter SM, Gross SJ. Glucose-6-phosphate dehydrogenase deficiency. eMedicine [Internet] 2005, Aug 29 [cited in2009,Nov20]. Available from http://emedicine.medscape.com/artical/200390overview.

8. Kessler II. A genetic relationship between diabetes and cancer. The Lancet. 1970; 1: 218-220.

9. Wikipedia Glucose-6-phosphate dehydrogenase deficiency. English Wikipedia.Internet]. 2010 March22.Availablefrom:http://en.wikipedia.org/ wiki/Gluose-6-phosphate-dehydrogenasedeficiency.

10. Chanmugam D, Frumin MA. Abnormal oral glucose tolerance response in erythrocyte Glucose-6Phosphate Dhydrogenase deficiency. N Eng J of Med. 1964; 271: 1202-04. 


\section{Article}

G6PD in Type 2 Diabetes

11. Saeed KhTh, Hamamy AH. Alwan SAA. Association of Glucose-6-Phosphate Dhydrogenase deficiency with Diabetes Mellitus. Diabetic Med.1985; 2: 11012.

12. Sarabesh. Role of oxidative stress in diabetes mellitus. [Internet] 2006; Aug 20: [Cited Jun 25]; Available from: http:/www.shvoong.com/exactscience/392987.

13. Wan Gwo-Hwa, Tsai Shu-Chen, Chiu Tsun-Yee Daniel.Decreased Blood activity at Glucose-6Phosphate Dehydrogenase. Associates with increased Risk for Diabetes Mellitus. Endocrine, 2002; 19: 191-195.

14. Chiu DTY, Cheng ML.Vitamin C in health and diseases. [Internet]. C 1997 [Cited 2009 Nov 4]. Available from: http://books.google.com/books.

15. Niazi GA. Glucose-6-phosphate dehydrogenase deficiency and diabetes mellitus. Int $\mathrm{J}$ of Hematol.1991; 54: 295-98.

16. Margaret P, Davidson J, Cockburn B.Glucose-6phosphate dehydrogenase activity in diabetes in Trinidad and Tobago. West Indian Med. J. 2001; 50: 34-5. 